\title{
Virtual Computer Technologies in Practice of Socio-Psychological Assistance toward the Unemployed People: Current State and Prospects of Researches
}

\author{
Galina I. Efremova ${ }^{1}$, Rimma M. Aysina ${ }^{1}$, Inna V. Kolotilova ${ }^{1}$, Zhanna A. Maksimenko ${ }^{1}$ \& Angelina A. \\ Shagurova ${ }^{1}$ \\ ${ }^{1}$ The North Caucasus Federal University, Russian Federation \\ Correspondence: Angelina A. Shagurova, The North Caucasus Federal University, Fundamental and Applied \\ Research Institute, 355009, Stavropol, Pushkina str., 1, Russian Federation. Tel: 79-68-595-0144. E-mail: \\ Linochka.88@mail.ru
}

Received: September 23, 2014 Accepted: October 30, 2014 Online Published: December 20, 2014

doi:10.5539/ass.v11n2p262

URL: http://dx.doi.org/10.5539/ass.v11n2p262

\begin{abstract}
In article the possibilities of application of the virtual computer technologies (VCT) in practice of a socio-psychological assistance to the population are considered. Achievements of modern science in a scope of systems of virtual reality in the "helping" professions are observed. Solving the psychological problems of the unemployed people can be optimized by means of VCT are discussed. The requirements to development of virtual training model which would promote quality improvement of social psychological assistance of toward the unemployed are formulated.
\end{abstract}

Keywords: socio-psychological assistance, unemployed, virtual computer technologies, virtual reality, virtual training model

\section{Introduction}

Ambiguous political situation and the changing socio-economic conditions of the population have led to the fact that unemployment became one of important problems of the modernity. According to data released by the Federal State Statistics Service of the Russian Federation (GKS) and the International Labour Organization, 202 million people of working age in the world have classified as unemployed. (Interfax.ru, 2014). In Russia 4,2 million people have referred to category of the unemployed. (GKS, 2014)

In researchers' judgment to scientists, unemployment entails a number of economic and socio-psychological consequences: an increase in crime; reduction in the standard of living; loss of skills as a result of long periods of professional activity; deterioration of relations in families of people who lost their jobs; deterioration of mental and physical health. (Zaytseva, 2010), (Gychev, 2011). In other words, crisis of employment can result to permanent maladjustment of the population, strengthening of political destabilization and social tension. Decrease in sharpness of problems possibly because of increase of social and economic welfare and owing to rendering the qualified socio-psychological assistance to citizens of Russia.

Traditional forms of consulting services in the field of employment of unemployed people can't fully satisfy the requirements of customers in need. The resolving consists in search of new forms of advisory work. Social and psychological consultation with application of the virtual computer technologies (VCT) is one of them. As a consequence of the objective process of informatization of society and absorbing the achievements of modern science, VCT in the twenty-first century are the most efficient, integrated, eco-friendly and efficient tools of improving the quality of social services.

\section{Opportunities of Using Virtual Computer Technologies in Social Practice}

Advantages of virtual reality technologies identified and substantiated in numerous studies of modern sociologists, social philosophers, culturologists and psychologists. (Goncharov, 2010; Nevesenko, 2011; Kurbanova, 2013; Malyshko, 2008; Yukhvid, 2010; Lopatinskaya, 2013; Voyskunsky \& Menshikova, 2008; Churayeva, 2009; Kozhanova, 2009; Zinchenko, Menshikova, Bayakovsky, Chernorizov, \& Voyskunsky, 2010; Kolotilova, 2010; Aime, Cotton, Guitard, \& Bouchard, 2012; Riva \& Mantovani, 2012). 
In article Y. P. Zinchenko and coauthors the following distinctive features of virtual technologies in comparison with traditional methods of psychological science and practice are accented (Zinchenko et al., 2010)

- high ecological validity: possibility of successful transferring of knowledge and experience which are got in virtual environment, in a real vital context thanks to creation in a cyberspace of the stimulus environment which is most approached to the natural;

- complete control of attention of the observer (user) at the expense of brightness, dynamism and interactivities of the virtual environment;

- possibility of programming of the virtual environment, presentation of various stimuli with controlled parameters, selective allocation of required stimulation, creation of polymodal stimulation, and also possibility of control of structure and sequence of emergence of virtual objects;

- possibility of creation of such virtual reality which not only models constant reality or reflects it, but also allows to provide to the user effect of presence at such conditions and circumstances which are unattainable or dangerous in real life; this possibility of VCT allows, for example, to carry out training of disaster treatment specialists working in emergency situations, and also can be very demanded in educational process as opens prospects of development of a difficult training material in a "game" form;

- providing feedback in real time, for example, due to use of the special display, allowing to carry out actions with virtual objects and at once visually to show the result.

At the present time psychotherapeutic practice is the most developed scope of VCT in "helping" professions. Systems of the virtual reality (VR) effectively apply in therapy of phobias and panic frustration, in remedial of a traumatic stress, in a psychological assistance to patients with violations of food behavior, psychotherapy of tobacco dependence, psychological rehabilitation of alcoholics and drug addicts. (Zinchenko et al., 2010; Kolotilova, 2010; Hoffman, 2004; Selisskaya, Voyskunsky, Ignatyev, \& Nikitin, 2004; Eichenberg \& Wolters, 2012; Bordnick et al., 2005; Calhoun, Carvalho, \& Astur, 2005).

In practice of career counselling and psychological support of unemployed citizens, application of VCT is extended in much smaller degree.

Some consulting companies offer virtual computer simulators, which allow the client to answer in an online mode the most typical questions of interview, as a commercial product. Thus, the client chooses one or several options of the answer from the offered. The answer to each of questions has accompanied by the subsequent text comment concerning its adequacy and relevance in an interview situation. (MentalSkills.ru, 2014). The monotony of a stimulus material and use for feedback only one (verbal) information channel is the disadvantage of similar exercise machines. The principles of dynamism, polymodal stimulation, variability of feedback and ensuring different levels of interaction with the virtual partner remain unfulfilled in virtual exercise machines of this type.

Today in the sphere of the state support of unemployed citizens from departments and the centers of employment, the use of virtual reality has reduced to on-line psychological testing. (Department of Labour and Employment of the population of Moscow, 2014). This technology is considerably optimizes the process of a psychological assessment of professional tendencies and professionally important qualities of the people interested in employment. However, it leaves without decision some other important problems of a social psychological assistance to this contingent of clients.

\section{Psychological Problems of Unemployed and Possible Solutions}

Despite an active state policy in the field of a solution of the unemployment problem, a number of negative tendencies in this sphere characterizes the situation. First of all, incomplete using of labor force, deterioration of socio demographic and vocational qualification of workers, an involvement of a significant part of the population into informal sector of economy, the absence of a stable social norms concerning a profession, low level of social, searchig and labor activity of part of the population it is necessary to refer to them. (Efremova, 2002; Nesterova, 2011; Petrosyan, 2011; Potutkova, 2011; Rakhimova, 2009; Seryogina, 2006).

Further deepening of these tendencies will lead to serious socio-political and economic outcomes. It demands continuation of searching of solutions of a problem of unemployment from various scientific and practical positions.

Among that heterogeneous group of the unemployed people allocate social and demographic groups of the population experiencing the greatest difficulties at employment: 
- people with long (more than one year) break in work, including women, long time being in a leave the child care;

- disabled people;

- unemployed of pre-retirement age;

- young people without work experience (in particular, persons from among orphan children and children without parental support, at the age up to 23 years).

These categories of unemployed citizens have significant features. Job placement problems of the unemployed people having a considerable break in professional activity, are caused by that the increase in the period of unemployment conducts to steady decrease in search activity and initiative, partial loss of skills in communicative assertiveness, self-management. (Potutkova, 2011; Levin \& Nalimova-Bolshakova, 2002).

Besides, many of them address in employment services during midlife crisis, being characterized by revaluation of the life and professional path and change of career orientations. In this regard, the help to unemployed citizens requires great skills and should be tailored to age-related changes and possible changes in the field of professional interests, which may be in a conflict with previous education and professional experience.

It is necessary to consider that obvious refusal of former interests may be the result of adverse reactive mental states, like for example depression, apathy, emotional burn out and negativism. (Aysina \& Savenko, 2013). In this case the treatment work directed on identification and the analysis of the reasons of such states updating of a personal resource of the unemployed, rendering the help to it in development of effective strategies for coping behavior will allow restoring the lost interest in a profession and will promote a successful professional readaptation.

On the other side, in the process of diagnostic and remedial work may be identified deep and sustained conflict between the personality of unemployed person and his profession. This obstacle disturbs effective employment. A talk with an unemployed person about vocational retraining for a new profession or new qualification may become a rational way to the solution of this problem.

The problem of employment of disabled people is caused not only insufficient readiness of employers to accept people with disabilities as equal participants of a labor market. The part of disabled people is not ready to take itself as full-fledged members of society with the all rights and duties, according to the Constitution of the Russian Federation. It also represents a problem. (Petrosyan, 2011).

Thus, HR and employment center, engaged career guidance counselling, have to consider both social stereotypes concerning disabled people and low level of motivation to employ from competitors side and probability their "rental income attitude". The essence of resigned attitude consists in possible aspiration of people with disabilities to take maximum benefits from the state. It is a question as of softer working conditions guaranteed by the law (for example, the reduced working week, bigger annual vacation), and of the requirement of the special relation caused by disability. Sometimes employees with disability demand for themselves "indulgences" concerning labor discipline or a priority at distribution of non-material bonuses in the organization.

According to these facts, it is important to help a disabled person in job seeking to understand that success is connected with ability to convince the potential employer of their wish and readiness to work on an equal basis with all members of labor team.

Psychological problems of unemployed people of pre-retirement age are often connected with insufficient orientation in modern rules and standards of behavior in job search and passing of interviews, the dogmatic attitude to the social experience, which manifests in narrow and rigid scale of behavioral skills and ways of communication with the recruiter and the potential employer. (Potutkova, 2011).

The young unemployed people, who have not any professional experience meet the negative reaction of the employer. This situation is frequently extends on such category as former orphans and children without parental support at the age up to 23 .

First, the negative attitude of potential employers towards this category of youth is explained by stereotypic prejudices: leavers of specialized residential institutions for orphans perceive as the persons inclined to deviant behavior, insufficiently reliable, irresponsible, inclined to manipulations and sabotage.

Secondly, the unwillingness of employers to employ this category of young people may be determined by the negative impression made by these competitors on interview. 
Thus, in the course of socio-psychological support of young people it is necessary to consider a number of specific circumstances. It especially concerns to those of them who is looking for a work the first time.

Among the Russian youth the stereotype of orientation to receiving various opportunities in education, rest, housing without application of own efforts is eradicated not completely. As a rule, parents provide such conditions. In this regard, attitude on receiving the specified vital benefits as remuneration for the work has not formed at youth. Besides, paternalistic attitude in relation to youth from society and parents continues to work in Russia. According to the attitude, all decisions for the youth made by their parents. Parents resolve issues like a life path, a study place, choice of profession etc. As a result - the low motivation to work has formed at youth. (Efremova, 2002; Rakhimova, 2009; Seryogina, 2006).

As for young people from among orphan children and the children who are bringing up without care of parents, their dependant position is explained, in our opinion, by other reasons.

During education in residential care they have no possibility of receiving experience of life in a family. Thus, the previous experience of the relation with parents, in most cases, is traumatic. In this regard, such children may project the offenses and claims to parents on public institutes, in particular, on the enterprises and the organizations in which they could work. In real life, similar projections have expressed in aggressive and haughty or in closed, passive behavior on interview.

The young unemployed directly or indirectly show the specified tendencies. The specified tendencies shown by the young unemployed conduct to rejection of the employer or to refusal of offered vacancy by the competitor himself. From the very beginning the competitor has inadequately focused on high earnings and a prestigious position.

Specialists of employment centers can offer to young people the actions promoting formation of professional intentions, value-normative representations and skills of social behavior for the purpose of increase of efficiency of employment. These problems successfully solve in the course of individual professional counseling and group training activities. (Rakhimova 2009; Seryogina, 2006).

The psychotechnics, aimed at the development of assertive behavior skills (for example, skills of assertive and responsible behavior at interview with the employer, skills of coping behavior in situations when an employer rejects) are necessary to allocate in separate group of consulting specialist activities. These psychotechnics have directed on increasing of efficiency of behavior of all groups of unemployed citizens on a labor market. It's also important to pay attention to the development of skills of a self-management for these groups (decision-making, time management, etc.).

Psychologists and specialists of employment services should to explain the unemployed people the fact that for the employer any specialist has to be economically expedient. It is the important step in work with clients of "difficult" social and demographic categories. In other words, benefit from work of the employee has to be more, than costs of his contents. In this regard, during interview the applicant for a job has to convince the employer that the professionalism and the willingness to work is worth more than a salary and the maintenance of a workplace of the competitor.

Summarizing, we formulate the basic tasks of social-psychological assistance to the unemployed people:

- overcoming of personal and professional maladjustment, rental income attitude;

- actualization of personal potential;

- formation of readiness to take the responsibility for changing their life situation;

- identification, analysis and elaboration of inefficient behavioral strategies used during interview with potential employers;

- training to skills of assertive behavior and methods of effective business communication.

The traditional solution of these tasks is possible in a format of individual psychological counseling, social and psychological trainings, professional retraining. All these activities can be effective and efficient as confirmed in numerous scientific studies conducted both in our country and abroad (Efremova, 2002; Nesterova, 2011; Potutkova, 2011; Levin \& Nalimova-Bolshakova, 2002).

At the same time, these activities require significant financial, temporal and personnel resources. Often the services realizing these resources don't have them.

Solution of this difficult situation we see in implementation of virtual computer technologies into process of interaction between employment centers specialists and their clients, unemployed. 


\section{The Virtual Training Model as a Means to Facilitate the Employment Process}

As it was mentioned above, one of the most serious problems, interfering effective employment of the unemployed people, is the lack of effective social communication skills or their absence as a result of the long unemployment period. This problem is more and more actual, because many companies create emotional tension during the interview process, implement into conversation with the applicant "stress interview" elements. Unsuccessful experience of such kind of interview seriously decreases the applicant's professional and personal self-estimation. It leads to development of a depressive behavior mode, to substantial motivation decrease to further employment and the inhibition of any activity in this direction.

In this regard the development of the virtual computer technology primarily promoting formation of communicative assertiveness skills, which need to be shown during interview with the recruiter, the potential employer or his representative.

The realization of this technology is possible on the basis of the virtual training model, the efficacy of which involves its compliance with the following requirements:

1) Various virtual images of the recruiter and various scenarios of conversation design, and also possibility to choice several options of interview of different complexity levels. These levels are defined by a combination of the following conditions:

- the behavior of a recruiter, that ranges from accepting and supporting too aggressive and arrogant;

- category (level) of job vacancy for which is the applicant claimed; depending on this parameter, the content of interview ranges from the prime structured interview (for the linear employee) to the interview on competences (for managers of different levels).

Thus, the model should include different options of expert procedures: from unambiguously formulated questions and simple test tasks to more composite tasks which have no clearly correct answers, such as projective questions and case-interview elements.

2) Possibility of register and the analyze all complex of information got from the applicant. It is needed to estimate not only a regularity of answers to this or that question, but also and reaction rate, the common physiological indicators of the applicant during a virtual interview (HR, GSR), to carry out general analysis of nonverbal communication by means of voice (tone, tempo of speech, loudness, quality of a pronunciation), features of the motor areas (mobility, amplitude of gesticulations, features of mimic reactions) is required.

3) Presence in scenarios of the interview incorporated in the model, at least five blocks allowing to evaluate the candidate's proposed position in the following parameters:

- motivation of professional activity;

- basic (common) abilities: attention, memory, mathematical and verbal abilities;

- special abilities (specialized professional knowledge and abilities);

- social competences (ability to work in a team, communicative flexibility, diplomacy, etc.);

- personal qualities (are defined depending on requirements to a position).

4) Possibility to provide to the applicant a feedback on complex verbal and nonverbal indexes. During the interactive interview it may be expressed in the following comments: "You are too worried!" or "You are working too slowly!" At the end of the interview the applicant should be offered a summary report on the results of work, which includes the description of successfully passable stages and the indications of its resource qualities, as well as mistakes and recommendations for their correction.

5. Possibility to add in the summary report some generalized data on dynamics of an emotional condition of the applicant in the course of the virtual interview, which will allow to define the subjects causing atypical emotional reactions and demanding padding attention and study.

Technical side of realization the offered virtual training model consists in development of the software product, which would allow:

- to create and modify the virtual image of the recruiter (age, sex, clothes, a voice timbre), and also to reproduce the text of the scenarios of interview with a choice of a voice type and its emotional coloring;

- to create and modify various scenarios of carrying out interview, firstly, depending on the demanded complexity level, and secondly, on the specifics of the competitor's answers and his nonverbal indexes; 
- to analyze the online information entering from fixing sensor at the time of carrying out interview and realization of test tasks, and to compare it to the established norms or to other data (data got from other competitors or other interviews of the same competitor, but carried out earlier).

Implementation of the training virtual model corresponding to the stated requirements in practical work of the employment centers and other HR departments which work with unemployed persons would greatly optimize the process of employment due to a significant reduction of time expenditure of psychologist work and significantly increase its efficiency.

However, it is necessary to remember that despite the obvious advantages of the virtual computer technologies, their application is only part of the common strategy of a social-psychological assistance and may it complete only. The professionalism of the qualified consultant impossible to be replaced in any way.

\section{Conclusions}

1) The Virtual Computer Technologies (VCT) are gaining ground on social and psychological practice (compared to traditional methods) due to the advantages such as ecological validity, dynamism, interactivity, possibility of programming of the virtual environment, creation of polymodal stimulation, ensuring feedback coupling in real time.

2) So far the most developed area of the VCT application in "helping" professions is psychotherapeutic practice. The systems of the virtual reality used in this field is an effective resource of for improving the quality of psychological care for alcoholic and drug dependences, eating disorders, phobias, panic disorders, traumatic reactions to stress.

3) In the field of a socio-psychological assistance to the unemployed people, the application of VCT is confined mainly to psychological testing in on-line mode that considerably optimizes process of professional orientation counseling of the people interested in employment, but leaves with no decision some other important tasks which are actual for these clients.

4) On the basis of data of the theoretical analysis as the task demanding the priority decision, it is possible to conclude that low communicative assertiveness of the unemployed people needed to be overcame. Thus, a problem of development VCT, allowing to provide efficient training in a field of assertive behavior skills is getting actual.

5) The implementation of this virtual computer technology, promoting formation of communicative assertiveness skills, may be carried on the basis of the virtual training model out. The model efficacy assumes the compliance to the principles of interactivity and dynamism of the virtual environment, polymodality of stimulation, variability of a feed-back and providing different levels of interaction with virtual partner. The implementation of the model in the practice of the social-psychological assistance to unemployed will allow to increase significantly its effectiveness and to reach the economy of financial, life and personnel resources.

\section{Gratitude}

This article was prepared as part of the task $\# 25.1815 .2014 / \mathrm{K}$ of 11.07 .2014 , on performance of the research work within the project framework of the state assignment in the field of scientific activity.

\section{References}

Aime, A., Cotton, K., Guitard, T., \& Bouchard, S. (2012). Virtual Reality and Body Dissatisfaction Across the Eating Disorder's Spectrum. In C. Eichenberg (Ed.), Virtual Reality in Psychological, Medical and Pedagogical Applications (pp. 109-122). Retrieved from http://www.intechopen.com/books/virtual-reality -in-psychological-medical-and-pedagogical-applications/virtual-reality-and-body-dissatisfaction-across-theeating-disorder-s-spectrum

Aysina, R. M., \& Savenko, T. S. (2013). Possibilities of application of psychodiagnostic methods in the course of rendering psychological assistance to jobless citizens with the long-lived break in work. In G. I. Efremova (Ed.), Actual problems of professional self-realization. Materials of student's scientific conference of Faculty of psychology (pp. 160-164). Moscow, RF: Russian state social University.

Bank interactive profession description. Department of Labour and Employment of the population of Moscow. Informational portal. Retrieved from http://www.prof.labor.ru

Bordnick, P. S., Traylor, A. C., Graap, K. M., Hilary, L., \& Brooks, J. (2005). Virtual Reality Cue Reactivity Assessment: A Case Study in a Teen Smoker. Applied Psychophysiology and Biofeedback, 30, 187-193. http://dx.doi.org/10.1007/s10484-005-6376-0 
Calhoun, V. D., Carvalho, K., \& Astur, R. (2005). Using Virtual Reality to Study Alcohol Intoxication Effects on the Neural Correlates of Simulated Driving. Applied Psychophysiology and Biofeedback, 30, 285-306. http://dx.doi.org/10.1007/s10484-005-6384-0

Churayeva, N. S. (2009). Diagnostics of motivation of the introduction of individuals in the virtual communities. The Messenger of University (The State University of Management), 6, 126-127.

Efremova, G. I. (2002). Psychological ensuring professional support of jobless women. Unpublished doctoral dissertation. Tver state University, Tver, RF.

Eichenberg, C., \& Wolters, C. (2012). Virtual Realities in the Treatment of Mental Disorders: A Review of the Current State of Research. In C. Eichenberg (Ed.), Virtual Reality in Psychological, Medical and Pedagogical Applications (pp. 35-64). Retrieved from http://www.intechopen.com/books/virtual-reality-inpsychological-medical-and-pedagogical-applications/virtual-realities-in-the-treatment-of-mental-disorders-a -review-of-the-current-state-of-research

Federal State Statistics Service of Russian Federation. Retrieved from http://www.gks.ru/bgd/free/b04_03/ IssWWW.exe/Stg/d03/56.htm

Goncharov, D. K. (2010). Features of the introduction of Internet technologies in the educational process: A sociological aspect. Unpublished $\mathrm{PhD}$ thesis. Moscow city pedagogical University, Moscow, RF.

Gychev, A. V. (2011). Organization, forms and methods of the psychoprophylactic help to the unemployed. Siberian messenger of psychiatry and addictology, 1, 108-111.

Hoffman, X. (2004). Salutary virtual reality. In the science world, 11, 36-43.

Kolotilova, I. V. (2010). Possibilities of use of computer games for development of success of the person. In V. P. Andryushchenko (Ed.), NPU named after M. P. Dragomanov: Scientific journal of the National pedagogical University named after M. P. Dragomanov (pp. 92-98), Kiev, Ukrain.

Kozhanova, I. V. (2009). Engineering and psychological projection of the software of activity of staff of tax authorities. In V. A. Bodrov, \& A. L. Zhuravlev (Eds.), Actual problems of psychology of work, human engineering and ergonomics (pp. 491-506). Moscow: The Institute of psychology of the Russian Academy of Sciences.

Kurbanova, L. M. (2013). The person informational-Far-East version. The Modern researches of social problems, 3. Retrieved from http://www.journal-s.org/index.php/sisp/article/view/3201315

Levin, S. F., \& Nalimova-Bolshakova, I. Y. (2002). Psychological influence of unemployment. In M. A. Gulina (Ed.), Psychology of social work (pp. 251-271). SPb: JSC "Publishing house "Piter".

Lopatinskaya, T. D. (2013). Virtual and game tendency of development of the modern culture: Threat of cultural safety or new prospects. The Person in culture space: The IV Russian culturological congress with the international participation (St. Petersburg, on October 29-31, 2013). Theses and performances of participants. Retrieved from http://www.culturalnet.ru/main/congress_person/1106

Malyshko, A. A. (2008). Spirit, soul and the virtual reality. Messenger of MGTU, 1, 122-125.

Mental Skills-international project of distance learning (eLearning). Retrieved from http://www.mental-skills.ru/case/53735/pass.html

Nesterova, A. A. (2011). The social and psychological concept of viability of youth in a work loss situation. Unpublished doctoral dissertation. Russian state social University, Moscow, RF.

Network edition "Interfax". Retrieved from http://www.interfax.ru/business/352795

Nevesenko, E. D. (2011). Features of socialization of the person in the virtual reality. In M. N. Makarova (Ed.), Social sciences in the transformed society: Materials of the All-Russian scientific and practical conference on October 20-21 (pp. 169-172). Izhevsk: Publishing house "Udmurt University".

Petrosyan, V. A. (2011). Integration of disabled people into the Russian society. Unpublished doctoral dissertation. Russian state social University, Moscow, RF.

Potutkova, S. A. (2011). Interrelation of social intelligence and adaptability of the unemployed at job search stages. Unpublished $\mathrm{PhD}$ thesis. Russian state social University, Moscow, RF.

Rakhimova, G. A. (2009). Cognitive and strong-willed features of sovladayushchy behavior of the unemployed (on the example of the people 20-30 summer age who have lost work). Unpublished $\mathrm{PhD}$ thesis. Russian state social University, Moscow, RF. 
Riva, G., \& Mantovani, F. (2012). Being There: Understanding the Feeling of Presence in a Synthetic Environment and Its Potential for Clinical Change. In C. Eichenberg (Ed.), Virtual Reality in Psychological, Medical and Pedagogical Applications. Retrieved from http://www.intechopen.com/books/virtual-reality -in-psychological-medical-and-pedagogical-applications/being-there-understanding-the-feeling-of-presence -in-a-synthetic-environment-and-its-potential-for-c

Selisskaya, M. A., Voyskunsky, A. E., Ignatyev, M. B., \& Nikitin, A. V. (2004). In A. V. Chugunov (Ed.), Application of the virtual reality as psychotherapeutic means for the help suffering from psychological phobias. The research project. In Technologies of informational society - the Internet and the modern society: Works VII of the All-Russian joint conference (on November 10-12, 2004) (pp. 38-40). SPb.: Saint-Petersburg state University.

Seryogina, A. A. (2006). Social and psychological conditions of overcoming of infantility at jobless youth. Unpublished PhD thesis. Russian state social University, Moscow, RF.

Voyskunsky, A. E., \& Menshikova, G. Y. (2008). About use of systems of the virtual reality in psychology. Vestnik Moskovskogo Univesiteta, Psychology, 1, 22-36.

Yukhvid, A. V. (2010). Virtualnost virtualogiya. Policy and society, 10(76), 56-61.

Zaytseva, V. B. (2010). Psychological risk factors of a disadaptation of the unemployed. Unpublished PhD thesis. St.Peterburg State University, SPb., RF.

Zinchenko, Y. P., Menshikova, G. Y., Bayakovsky, Y. M., Chernorizov, A. M., \& Voyskunsky, A. E. (2010). Technologies of the virtual reality: Methodological aspects, achievements and prospects. National psychological magazine, 1(3), 54-62.

\section{Copyrights}

Copyright for this article is retained by the author(s), with first publication rights granted to the journal.

This is an open-access article distributed under the terms and conditions of the Creative Commons Attribution license (http://creativecommons.org/licenses/by/3.0/). 